\title{
Staphylococcus aureus pigmentation is not controlled by Hfq
}

\author{
Wenfeng Liu(B), Pierre Boudry, Chantal Bohn (1) and Philippe Bouloc *i]
}

\begin{abstract}
Objective: The golden color of Staphylococcus aureus is due to the synthesis of carotenoid pigments. In Gram-negative bacteria, $\mathrm{Hfq}$ is a global posttranscriptional regulator, but its function in S. aureus remains obscure. The absence of $\mathrm{Hfq}$ in S. aureus was reported to correlate with production of carotenoid pigment leading to the conclusion that $\mathrm{Hfq}$ was a negative regulator of the yellow color. However, we reported the construction of $h f q$ mutants in several $S$. aureus strains and never noticed any color change; we therefore revisited the question of Hfq implication in S. aureus pigmentation.
\end{abstract}

Results: The absence or accumulation of $\mathrm{Hfa}$ does not affect S. aureus pigmentation.

Keywords: Staphylococcus aureus, Hfq, Pigmentation, Staphyloxanthin, Regulation

\section{Introduction}

Staphylococcus aureus is a major pathogen responsible for numerous diseases from minor skin infection to septicemia, affecting humans and other animals. Its name "aureus" comes from the golden color of strains that express carotenoid pigments [1]. These pigments contribute to oxidative stress and neutrophil resistance, and virulence [2]. The carotenoid biosynthetic operon (crt$M N O P Q$ ) leading to the synthesis of staphyloxanthin is regulated by $\sigma^{\mathrm{B}}[3,4]$, an alternative $\sigma$ factor that also controls a large number of general stress genes. $\sigma^{\mathrm{B}}$ activity depends on RsbU, its positive regulator [5, 6]. Numerous strains, including the $S$. aureus model NCTC8325, have $r s b U$ mutations that prevent $\sigma^{\mathrm{B}}$ activity and $c r t$ operon expression, such that colonies are white. In addition, mutations in 37 genes were shown to result in the loss of a yellow pigmentation [5, 7].

Hfq is an RNA chaperone needed for activity of numerous regulatory RNAs in Gram-negative bacteria [8]. However, its role in Gram-positive bacteria, with the

*Correspondence: philippe.bouloc@cnrs.fr

Université Paris-Saclay, CEA, CNRS, Institute for Integrative Biology of the Cell (I2BC), 91198 Gif-sur-Yvette, France exception of Clostridium difficile [9], remains enigmatic [10]. Hfq functionality from different species is often tested by interspecies complementation tests. However, expression of $h f q$ genes from Gram-positive bacteria $S$. aureus and Bacillus subtilis in Salmonella could not compensate the absence of endogenous $h f q$, indicating a functional difference between Gram positive and negative Hfq $[11,12]$.

We previously compared phenotypes of $S$. aureus $h f q$ mutants with their isogenic parental strains and observed no detectable difference associated with the absence of Hfq in the tested conditions [13]. However, our results were partly challenged by a publication reporting that carotenoid pigment production was increased in $h f q-$ negative strains [14]. Here we use nine different $S$. aureus strains to show that Hfq absence or overexpression has no effect on pigment expression.

\section{Main text \\ Methods}

Bacterial strains, plasmids and growth conditions

Bacterial strains, plasmids and primers used in this study are listed in Table 1. Allelic replacements of $h f q^{+}$by $\Delta h f q::$ cat were either performed by $\phi 11$-phage

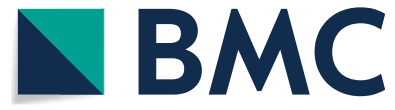

(c) The Author(s) 2020. This article is licensed under a Creative Commons Attribution 4.0 International License, which permits use, sharing, adaptation, distribution and reproduction in any medium or format, as long as you give appropriate credit to the original author(s) and the source, provide a link to the Creative Commons licence, and indicate if changes were made. The images or other third party material in this article are included in the article's Creative Commons licence, unless indicated otherwise in a credit line to the material. If material is not included in the article's Creative Commons licence and your intended use is not permitted by statutory regulation or exceeds the permitted use, you will need to obtain permission directly from the copyright holder. To view a copy of this licence, visit http://creativeco mmons.org/licenses/by/4.0/. The Creative Commons Public Domain Dedication waiver (http://creativecommons.org/publicdomain/ zero/1.0/) applies to the data made available in this article, unless otherwise stated in a credit line to the data. 
Table 1 Staphylococcus aureus strains, plasmids and primer used for this study

\begin{tabular}{|c|c|c|}
\hline Strain name & Key features & Reference or construction \\
\hline RN4220 & Transformable by DNA from E. coli & {$[25]$} \\
\hline SAPhB5 & RN4220 $\Delta h f q:: c a t$ & [13] \\
\hline NCTC8325 & Clinical isolate & [26] \\
\hline SAPhB224 & NCTC8325 $\Delta h f q::$ cat & NCTC $8325+\varphi 11($ SAPhB5) \\
\hline NCTC8325-4 & NCTC8325 $\Delta \varphi 11 \Delta \varphi 12 \Delta \varphi 13$ & {$[27]$} \\
\hline SAPhB197 & NCTC8325-4 $\Delta h f q::$ cat & NCTC8325-4+ $+11($ SAPhB5) \\
\hline RN6390 & NCTC 8325-4 $\varphi 6390$ & {$[28]$} \\
\hline SAPhB22 & RN6390 $\Delta h f q:: c a t$ & [13] \\
\hline HG001 & NCTC8325 rsbU repaired & [22] \\
\hline SAPhB199 & HG001 $\Delta h f q:: c a t$ & $\mathrm{HG} 001+\varphi 11(\mathrm{SAPhB5})$ \\
\hline HG002 & NCTC8325 tcaR repaired & [22] \\
\hline SAPhB201 & $\mathrm{HG002} \Delta h f q:: \mathrm{cat}$ & $\mathrm{HGO02}+\varphi 11(\mathrm{SAPhB5})$ \\
\hline HG003 & NCTC8325 rsbU and tcaR repaired & [22] \\
\hline SAPhB203 & HG003 $\Delta h f q:: c a t$ & $\mathrm{HG} 003+\varphi 11(\mathrm{SAPhB5})$ \\
\hline $\mathrm{COL}$ & Methicillin resistant clinical isolate & [29] \\
\hline SAPhB16 & COL $\Delta h f q:: c a t$ & [13] \\
\hline Newman & Clinical isolate & [30] \\
\hline SAPhB17 & Newman $\Delta h f q:: c a t$ & [13] \\
\hline SAPhB142 & RN4220 pRMC2 & RN4220 + pRMC2 \\
\hline SAPhB248 & $\mathrm{RN} 4220 \mathrm{pRMC2Hfq}$ & $\mathrm{RN} 422 \mathrm{O}+\mathrm{pRMC2Hfq}$ \\
\hline SAPhB251 & RN4220 pRMC2HfqFLAG & $\mathrm{RN} 4220+$ pRMC2HfqFLAG \\
\hline SAPhB233 & HG003 pRMC2 & $\mathrm{HG} 003+\mathrm{pRMC2}$ \\
\hline SAPhB249 & HG003 pRMC2Hfq & $\mathrm{HGOO3}+\mathrm{pRMC2Hfq}$ \\
\hline SAPhB257 & HG003 pRMC2HfaFLAG & $\mathrm{HG} 003+\mathrm{pRMC} 2 \mathrm{HfqFLAG}$ \\
\hline Plasmid name & Key features & Reference/construction \\
\hline pRMC2 & Anhydrotetracycline (aTc) inducible promoter $\mathrm{P}_{\text {xyl/teto }}$ & [17] \\
\hline $\mathrm{pRMC2Hfq}$ & hfq inducible expression & See "Methods" \\
\hline pRMC2FLAG & $\begin{array}{l}\text { pRMC2 derivative for translational gene fusions with 3xflag coding } \\
\text { sequence }\end{array}$ & See "Methods" \\
\hline pRMC2HfaFLAG & hfq::3xflag inducible expression & See "Methods" \\
\hline Primer name & Sequence & Purpose \\
\hline 39 & GGGGTACCATGATTGCAAACGAAAAC & hfq amplification (with a Kpnl site) \\
\hline 49 & GGGGAATTCTTATTCTTCACTTTCAGTAGATGC & hfq amplification (with an EcoRl site) \\
\hline 856 & GGTACCGTTAACAGATCTGAG & pRMC2 amplification \\
\hline 918 & GCTTATTTTAATTATACTCTATCAATGATAGAG & pRMC2 and pRMC2FLAG amplifications \\
\hline 858 & TCAGATCTGTTAACGGTACCGGAATTAGCTTGCATGGAA & 3xflag amplification \\
\hline 919 & GATAGAGTATAATTAAAATAAGCGAGCTCGACTACAAAGACCA & 3xflag amplification \\
\hline 865 & GACTACAAAGACCATGACGG & pRMC2FLAG amplification \\
\hline 939 & GATAGAGTATAATTAAAATAAGCGTAAAAGGAGTCCGACAGATGA & hfa amplification for cloning in pRMC2FLAG \\
\hline 940 & CCGTCATGGTCTTTGTAGTCTTCTTCACTTTCAGTAGATGCTTG & hfq amplification for cloning in pRMC2FLAG \\
\hline
\end{tabular}

mediated transduction using RN4220 hfq::cat as a donor strain or by homologous recombination using pMAD $\Delta$ hfq::cat $[13,15]$. The $\Delta h f q:$ cat deletion in SAPHB5 was verified by Southern blot and subsequent $\Delta h f q:: c a t$ transductants were verified by PCR as described [13].
Engineered plasmids were constructed as described [16]. Conditional $h f q$ expression was obtained by cloning $h f q$ under the xyl/tetO promoter in pRMC2 [17] and pRMC2FLAG (Table 1). pRMC2Hfq allowing $h f q$ conditional expression was obtained as follows: pRMC2 and PCR-amplified $h f q$ (using primers 39/49 on HG003 
DNA) were KpnI-EcoRI digested and ligated together. pRMC2FLAG was engineered for conditional expression of 3xFLAG-tagged proteins as followed: pRMC2 and pSUB11 [18] were PCR-amplified using primers 856/918 and $858 / 919$, respectively. The two resulting products, i.e. pRMC2 and $3 x$ flag coding sequence, were assembled using the Gibson method [19]. pRMC2HfqFLAG, allowing conditional expression of Hfq::3xFLAG, was obtained as follows: pRMC2FLAG and $h f q$ HG003 were PCRamplified using primers 918/865 and 939/940, respectively. The two resulting products were assembled using the Gibson method.

Bacteria were grown in BHI medium (BD Difco, ref: 237500) at $37{ }^{\circ} \mathrm{C}$ under vigorous agitation. BHI solid media were obtained by the addition of Bacto Agar $15 \mathrm{~g} \mathrm{l}^{-1}$ (BD Difco, ref: 214010). For strains containing pRMC2 and derivatives, chloramphenicol (SigmaAldrich, ref: C0378) $5 \mu \mathrm{g} \mathrm{ml}^{-1}$ was added to media. Expression from pRMC2 and derivatives was achieved by anhydrotetracycline (aTc, Chemodex, ref: CDXA0197-M500) $250 \mathrm{ng} \mathrm{ml}^{-1}$ addition to growth media.

\section{Protein extraction, Western blotting and staphyloxanthin spectral measurement}

Overnight cultures were diluted 1000 times in fresh medium. After $3 \mathrm{~h}$, aTc was added. $10 \mathrm{~min}$ and $30 \mathrm{~min}$ later, cells were harvested by centrifugation $(16,000 \mathrm{~g}$ for $2 \mathrm{~min}$ ), resuspended in $400 \mu \mathrm{l}$ Tris $\mathrm{HCl}$ buffer $(50 \mathrm{mM}$, $\mathrm{pH}$ 6.8) and lysed using a FastPrep (3 cycles of $45 \mathrm{~s}$ at $6.5 \mathrm{~m} \mathrm{~s}^{-1}$ ). Cell debris was removed by centrifugation $(16,000 \mathrm{~g}$ for $10 \mathrm{~min})$. Protein concentration was determined by Bradford assays [20]. For each sample, $3 \mu \mathrm{g}$ of protein extract was separated on a polyacrylamide gel Blot $^{\mathrm{TM}} 4-12 \%$ Bis-Tris Plus, Invitrogen, ref: NW04122BOX). After electrophoresis, proteins were transferred to a polyvinylidene fluoride membrane (iBlot 2 PVDF Mini Stacks, Invitrogen ref: IB24002). For blotting and washing, an iBind ${ }^{\mathrm{TM}}$ Flex Western System (ref: SLF2000S) was used according to supplier's instructions. Membranes were probed with the primary polyclonal ANTI-FLAG antibody produced in rabbit (Sigma, ref: F-7425) at a 1/15,000 dilution. A rabbit secondary antibody conjugated to horseradish peroxidase (Advansta, ref: R-05072-500) was used at a 1/25,000 dilution. Bioluminescent signal was detected with the WesternBright ${ }^{\mathrm{TM}}$ ECL-spray (Advansta, ref: K-12040-D50) using a digital camera (ImageQuant ${ }^{\mathrm{TM}} 350$, GE Healthcare).

The $S$. aureus pigments were extracted as described [21]. In brief, strains were grown in BHI under vigorous agitation for $24 \mathrm{~h}$. Cells were harvested by centrifugation, the pellet was rinsed twice with sterile water and pigments were extracted by methanol. Absorbance between
330 and $550 \mathrm{~nm}$ was measured on a microplate reader (CLARIOstar BMG LABTECH).

\section{Results}

The absence of Hfq does not alter S. aureus pigmentation In 2010, Liu et al. reported that "deletion of $h f q$ gene in S. aureus 8325-4 can increase the surface carotenoid pigments" [14]. Their work was performed using an allele called $\Delta h f q-8325$ in which the $h f q$ coding sequence was replaced by a kanamycin cassette. The $h f q$ chromosomal deletion was constructed in strain RN4220 and then transduced into NCTC8325-4, RN6390, COL and ATCC 25923 by phage $\phi 11$. We constructed a similar $h f q$ deletion in RN4220, except that the $h f q$ coding sequence was replaced by a chloramphenicol resistant gene ( $\Delta h f q::$ cat); this allele was transduced into RN6390, COL and Newman by $\phi 11$-phage mediated transduction [13]. Note that RN4220, RN6390 and COL strains were used for both studies. As we did not notice a change of color when the $\Delta h f q::$ cat allele was introduced into these strains, this information was not reported [13]. In view of the previous report, we focused this work on the possibility that Hfq could affect $S$. aureus pigment expression.

NCTC8325 isolated in 1960 from a sepsis patient is the progenitor of numerous strains including NCTC8325-4 (cured of three prophages) which itself gave RN6390 and RN4220 [22]. As these descendants were mutagenized, they carry several mutations that may affect their phenotypes. NCTC8325 has a deletion of $11 \mathrm{bp}$ in $r s b U$ and a point mutation in tcaR. The derivatives HG001 (rsbU restored), HG002 (tcaR restored), HG003 (rsbU and $t c a R$ restored) were constructed to perform physiological studies in a non-mutagenized background [22]. All these NCTC8325 derived strains, except HG001 and HG003 (which have a functional $\sigma^{B}$ factor), give rise to white colonies (Fig. 1). In addition to those reported [13], we constructed $\Delta h f q::$ cat derivatives in NCTC8325, NCTC8325-4, HG001, HG002 and HG003 (Table 1). In contrast to results reported in Liu et al., deletion of the $h f q$ gene in all tested strain backgrounds had no effect on pigmentation (Fig. 1a). Note that COL, Newman are not NCTC8325 derivatives.

Spectral profiles highlighting S. aureus carotenoid production were determined as described [21] for three strains and their $h f q$ derivatives after growth for $24 \mathrm{~h}$ in BHI. HG003 and HG003 $\Delta h f q:$ :cat gave equivalent profiles with three pics characteristic of carotenoid production. In contrast, NCTC8325-4 and RN1 had spectra characteristic of no or very little carotenoid production. As expected from our visual observation (Fig. 1a), the spectra of $\Delta h f q$ derivatives did not differ from those of their respective parental strains (Fig. 1b). 


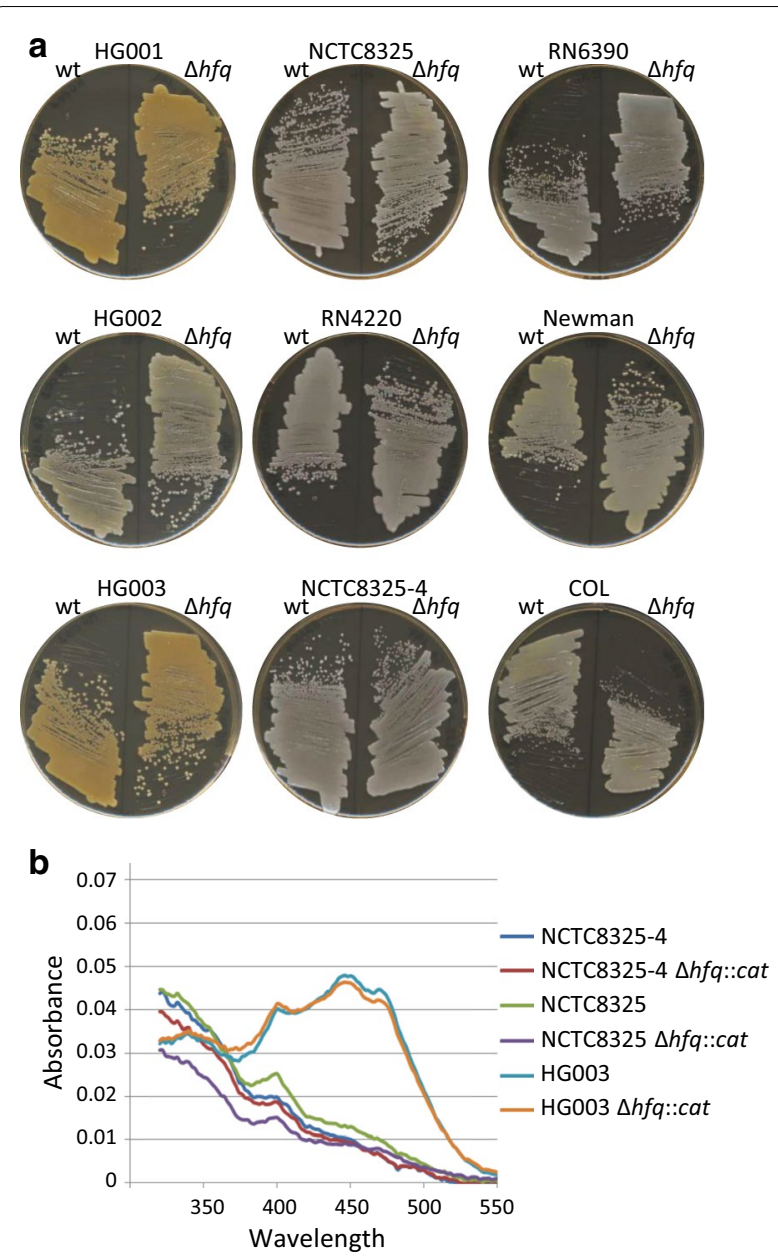

Fig. 1 Absence of Hfq does not affect S. aureus pigmentation. The indicated strains were grown overnight in $\mathrm{BH}$ and then a streaked on $\mathrm{BH}$ agar or $\mathbf{b}$ assayed for spectral profiles as described [21]

\section{Hfq overexpression does not alter S. aureus pigmentation}

In the above-described strains, $h f q$ is possibly poorly expressed, in which case $h f q$ deletions would not lead to detectable phenotypes. We therefore tested the effects of an inducible Hfq expression system on pigment production. If the absence of Hfq leads to yellow colonies as proposed [14], the presence of Hfq could lower pigment production and lead to white colonies. To address this point, $h f q$ was cloned under the control of the $\mathrm{P}_{\mathrm{xyl} /}$ tetO promoter in multi-copy plasmid pRMC2 [17] leading to pRMC2Hfq. $h f q$ expression in strains harboring pRMC2Hfq was induced upon aTc addition to media. To confirm that $\mathrm{P}_{\mathrm{xyl} / \mathrm{tet}}$ was effectively driving $h f q$ expression, a pRMC2Hfq derivative was engineered harboring a 3xflag sequence inserted in frame at the end of the $h f q$ open reading frame. The resulting plasmid, pRMC2HfqFLAG is a proxy for expression from pRMC2Hfq. HG003 was transformed with pRMC2, pRMC2Hfq

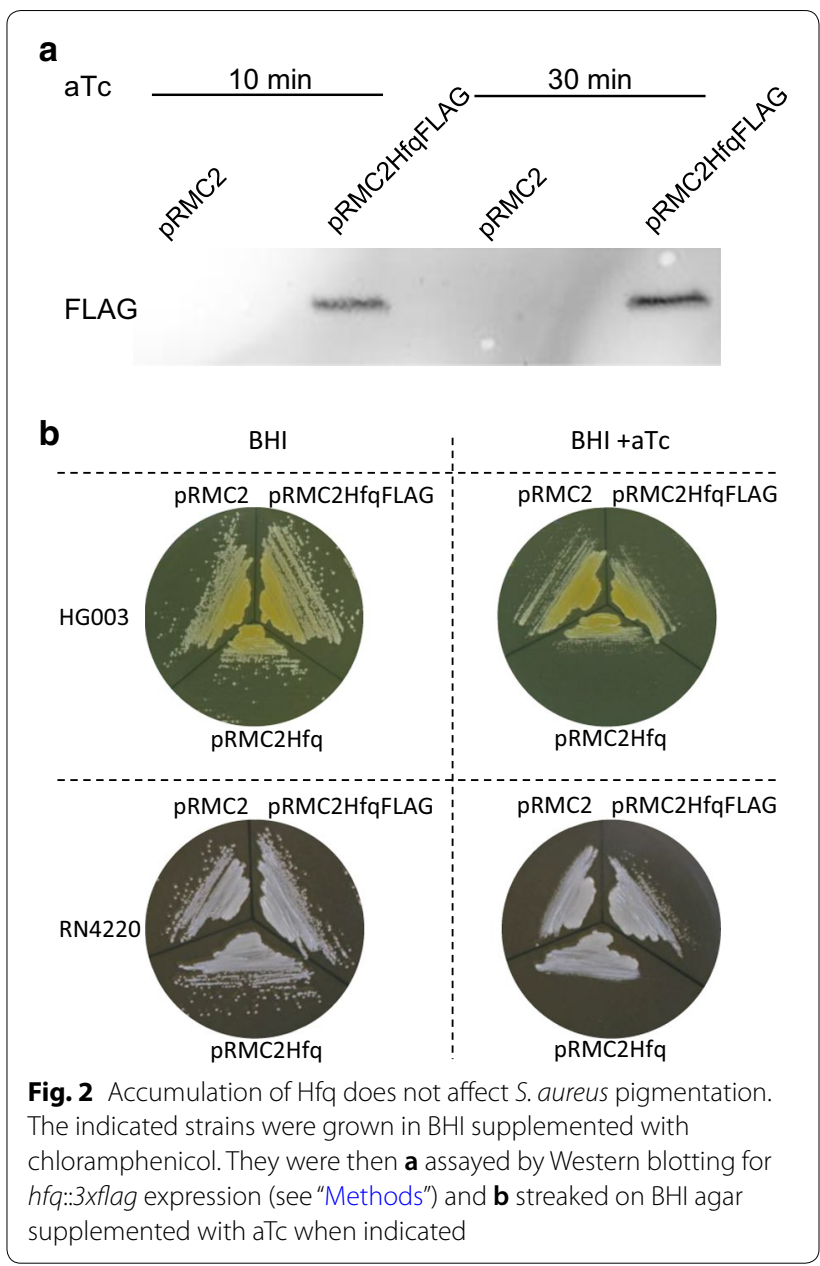

and pRMC2HfqFLAG. The protein Hfq::3xFLAG was detected upon aTc induction by western blotting using FLAG antibodies (Fig. 2a). We inferred from this result that addition of aTc to strains harboring pRMC2Hfq lead to Hfq synthesis. The RN4220 white and HG003 yellow colors were not affected by the presence of either pRMC2, pRMC2Hfq or pRMC2HfqFLAG and remained identical upon aTc addition to growth medium (Fig. 2b).

\section{Conclusion}

Our results show that neither the absence, nor the accumulation of $\mathrm{Hfq}$ affects pigmentation of S. aureus: Hfq does not appear to regulate staphyloxanthin synthesis. Our conclusions are supported by Tarrant $\mathrm{PhD}$ dissertation showing an NCTC8325 $h f q$ mutant that remained unpigmented [23]. Of note, Pseudomonas aeruginosa reportedly induces pigment production of a non-pigmented phenotypic variant of $S$. aureus, however, this effect was independent of $h f q$ transcription [24]. In addition, color variation in USA300 strain was screened in a genome-wide transposon mutant 
library, and the $h f q$ inactivation was not reported to affect S. aureus pigmentation [7].

While the $h f q$ gene is absent in some Firmicutes (e.g. Lactobacillales), it is conserved in all S. aureus, suggesting that it plays a crucial function, however not related to pigment expression. The quest to find the Staphylococcal Hfq function remains open.

\section{Limitations}

Our conclusion is in contradiction with Liu et al. results concerning the effect of Hfq on S. aureus pigmentation [14]. We cannot rule out that our observation is limited to specific $S$. aureus strains. However, we used an NCTC8325-4 $h f q$ derivative similar the one used in the previous study. Furthermore, the present results are strengthened by the construction of $h f q$ mutants in numerous $S$. aureus backgrounds. The discrepancy between our and Liu et al. 2010 [14] results, is a possible inadvertent selection of mutants with altered color patterns (as shown in [23]) in the former study.

\section{Abbreviations \\ PCR: Polymerase chain reaction; $\mathrm{BHI}$ : Brain heart infusion; aTc: Anhydrotetracycline.}

\section{Acknowledgements}

We thank Sandy Gruss, Annick Jacq and Yan Jing for critical reading of the manuscript, helpful discussions and warm support.

\section{Authors' contributions}

$\mathrm{PhB}$ designed the experiments and wrote the manuscript. WL, PiB and CB performed the experiments, analyzed data and revised the manuscript. All authors read and approved the final manuscript.

\section{Funding}

This work was funded by the Agence Nationale pour la Recherche (ANR) (Grant \# ANR-15-CE12-0003-01 "sRNA-Fit") and by the Fondation pour la Recherche Médicale (FRM) (Grant \# DBF20160635724"Bactéries et champignons face aux antibiotiques et antifongiques"). WL was the recipient of fellowships from the Chinese scholarship council. PiB was the recipient of fellowships from the FRM.

\section{Availability of data and materials}

All data generated or analyzed during this study are included in this published article. Strains and plasmids are available from the corresponding author on reasonable request.

\section{Ethics approval and consent to participate}

Not applicable.

\section{Consent for publication}

Not applicable.

\section{Competing interests}

The authors declare that they have no competing interests.

Received: 19 December 2019 Accepted: 1 February 2020

Published online: 07 February 2020

\section{References}

1. Marshall JH, Wilmoth GJ. Pigments of Staphylococcus aureus, a series of triterpenoid carotenoids. J Bacteriol. 1981;147(3):900-13.

2. Liu GY, Essex A, Buchanan JT, Datta V, Hoffman HM, Bastian JF, Fierer J, Nizet V. Staphylococcus aureus golden pigment impairs neutrophil killing and promotes virulence through its antioxidant activity. J Exp Med. 2005:202(2):209-15.

3. Bischoff M, Dunman P, Kormanec J, Macapagal D, Murphy E, Mounts W, Berger-Bachi B, Projan S. Microarray-based analysis of the Staphylococcus aureus sigmaB regulon. J Bacteriol. 2004;186(13):4085-99.

4. Pelz A, Wieland KP, Putzbach K, Hentschel P, Albert K, Gotz F. Structure and biosynthesis of staphyloxanthin from Staphylococcus aureus. J Biol Chem. 2005:280(37):32493-8.

5. Palma M, Cheung AL. sigma(Beta) activity in Staphylococcus aureus is controlled by RsbU and an additional factor(s) during bacterial growth. Infect Immun. 2001;69(12):7858-65.

6. Giachino P, Engelmann S, Bischoff M. Sigma(B) activity depends on RsbU in Staphylococcus aureus. J Bacteriol. 2001;183(6):1843-52.

7. Fey PD, Endres JL, Yajjala VK, Widhelm TJ, Boissy RJ, Bose JL, Bayles KW. A genetic resource for rapid and comprehensive phenotype screening of nonessential Staphylococcus aureus genes. MBio. 2013;4(1):e00537-12.

8. Vogel J, Luisi BF. Hfa and its constellation of RNA. Nat Rev Microbiol. 2011;9(8):578-89.

9. Boudry P, Gracia C, Monot M, Caillet J, Saujet L, Hajnsdorf E, Dupuy B, Martin-Verstraete I, Soutourina O. Pleiotropic role of the RNA chaperone protein $\mathrm{Hfq}$ in the human pathogen Clostridium difficile. J Bacteriol. 2014;196(18):3234-48.

10. Bouloc P, Repoila F. Fresh layers of RNA-mediated regulation in Grampositive bacteria. Curr Opin Microbiol. 2016;30:30-5.

11. Rochat T, Bouloc P, Yang Q, Bossi L, Figueroa-Bossi N. Lack of interchangeability of Hfq-like proteins. Biochimie. 2012:94(7):1554-9.

12. Rochat T, Delumeau O, Figueroa-Bossi N, Noirot P, Bossi L, Dervyn E, Bouloc P. Tracking the elusive function of Bacillus subtilis Hfq. PLOS ONE 2015;10(4):e0124977.

13. Bohn C, Rigoulay C, Bouloc P. No detectable effect of RNA-binding protein Hfa absence in Staphylococcus aureus. BMC Microbiol. 2007;7:10.

14. Liu Y, Wu N, Dong J, Gao Y, Zhang X, Mu C, Shao N, Yang G. Hfq is a global regulator that controls the pathogenicity of Staphylococcus aureus. PLoS ONE. 2010;5(9):e13069.

15. Le Lam TN, Morvan C, Liu W, Bohn C, Jaszczyszyn Y, Bouloc P. Finding sRNA-associated phenotypes by competition assays: an example with Staphylococcus aureus. Methods. 2017:117:21-7.

16. Rochat T, Bohn C, Morvan C, Le Lam TN, Razvi F, Pain A, Toffano-Nioche C, Ponien $\mathrm{P}$, Jacq $A$, Jacquet $E$, et al. The conserved regulatory RNA RsaE down-regulates the arginine degradation pathway in Staphylococcus aureus. Nucleic Acids Res. 2018:46(17):8803-16.

17. Corrigan RM, Foster TJ. An improved tetracycline-inducible expression vector for Staphylococcus aureus. Plasmid. 2009;61(2):126-9.

18. Uzzau S, Fiqueroa-Bossi N, Rubino S, Bossi L. Epitope tagging of chromosomal genes in Salmonella. Proc Natl Acad Sci USA. 2001;98(26):15264-9.

19. Gibson DG, Young L, Chuang RY, Venter JC, Hutchison CA 3rd, Smith HO. Enzymatic assembly of DNA molecules up to several hundred kilobases. Nat Methods. 2009;6(5):343-5.

20. Bradford MM. A rapid and sensitive method for the quantitation of microgram quantities of protein utilizing the principle of protein-dye binding. Anal Biochem. 1976;72:248-54.

21. Morikawa K, Maruyama A, Inose Y, Higashide M, Hayashi H, Ohta T. Overexpression of sigma factor, sigma(B), urges Staphylococcus aureus to thicken the cell wall and to resist beta-lactams. Biochem Biophys Res Commun. 2001;288(2):385-9.

22. Herbert S, Ziebandt AK, Ohlsen K, Schafer T, Hecker M, Albrecht D, Novick R, Gotz F. Repair of global regulators in Staphylococcus aureus 8325 and comparative analysis with other clinical isolates. Infect Immun. 2010;78(6):2877-89.

23. Tarrant EJ. The role of Hfq in S. aureus gene regulation. PhD. University of Leicester; 2013.

24. Antonic V, Stojadinovic A, Zhang B, Izadjoo MJ, Alavi M. Pseudomonas aeruginosa induces pigment production and enhances virulence in a white phenotypic variant of Staphylococcus aureus. Infect Drug Resist. 2013;6:175-86 
25. Nair D, Memmi G, Hernandez D, Bard J, Beaume M, Gill S, Francois P, Cheung AL. Whole-genome sequencing of Staphylococcus aureus strain RN4220, a key laboratory strain used in virulence research, identifies mutations that affect not only virulence factors but also the fitness of the strain. J Bacteriol. 2011;193(9):2332-5.

26. Novick RP, Richmond MH. Nature and interactions of the genetic elements governing penicillinase synthesis in Staphylococcus aureus. J Bacteriol. 1965;90:467-80.

27. Novick R. Properties of a cryptic high-frequency transducing phage in Staphylococcus aureus. Virology. 1967;33(1):155-66.

28. Novick RP. Molecular biology of the staphylococci. New York: VCH Publishers; 1990.

29. Gill SR, Fouts DE, Archer GL, Mongodin EF, Deboy RT, Ravel J, Paulsen IT, Kolonay JF, Brinkac L, Beanan M, et al. Insights on evolution of virulence and resistance from the complete genome analysis of an early methicillin-resistant Staphylococcus aureus strain and a biofilm-producing methicillin-resistant Staphylococcus epidermidis strain. J Bacteriol. 2005;187(7):2426-38.

30. Baba T, Bae T, Schneewind O, Takeuchi F, Hiramatsu K. Genome sequence of Staphylococcus aureus strain Newman and comparative analysis of staphylococcal genomes: polymorphism and evolution of two major pathogenicity islands. J Bacteriol. 2008;190(1):300-10.

\section{Publisher's Note}

Springer Nature remains neutral with regard to jurisdictional claims in published maps and institutional affiliations.
Ready to submit your research? Choose BMC and benefit from:

- fast, convenient online submission

- thorough peer review by experienced researchers in your field

- rapid publication on acceptance

- support for research data, including large and complex data types

- gold Open Access which fosters wider collaboration and increased citations

- maximum visibility for your research: over $100 \mathrm{M}$ website views per year

At BMC, research is always in progress.

Learn more biomedcentral.com/submissions 